\title{
Testis-Specific GTPase (TSG): An oligomeric protein
}

Sudeep Kumar ${ }^{1}$, Hyun Joo Lee ${ }^{2}$, Hee-Sae Park ${ }^{1}$ and Keesook Lee ${ }^{1 *}$

\begin{abstract}
Background: Ras-related proteins in brain (Rab)-family proteins are key members of the membrane trafficking pathway in cells. In addition, these proteins have been identified to have diverse functions such as cross-talking with different kinases and playing a role in cellular signaling. However, only a few Rab proteins have been found to have a role in male germ cell development. The most notable functions of this process are performed by numerous testis-specific and/or germ cell-specific genes. Here, we describe a new Rab protein that is specifically expressed in male germ cells, having GTPase activity.

Results: Testis-specific GTPase (TSG) is a male-specific protein that is highly expressed in the testis. It has an ORF of 1593 base pairs encoding a protein of 530 amino acids. This protein appears in testicular cells approximately 24 days postpartum and is maintained thereafter. Immunohistochemistry of testicular sections indicates localized expression in germ cells, particularly elongating spermatids. TSG has a bipartite nuclear localization signal that targets the protein to the nucleus. The C-terminal region of TSG contains the characteristic domain of small Rab GTPases, which imparts GTPase activity. At the N-terminal region, it has a coiled-coil motif that confers selfinteraction properties to the protein and allows it to appear as an oligomer in the testis.

Conclusion: TSG, being expressed in the male gonad in a developmental stage-specific manner, may have a role in male germ cell development. Further investigation of TSG function in vivo may provide new clues for uncovering the secrets of spermatogenesis.
\end{abstract}

Keywords: GTPase, Testis, RASEF

\section{Background}

Testicular development is marked by the development and differentiation of Sertoli cells, Leydig cells and germ cells. These developmental processes are strictly regulated by a well-coordinated program of gene expression [1-3]. During Spermatogenesis, the genetic information from male germ stem cells undergoes editing and reorganization and is finally distributed into spermatozoa. The most notable functions of this process are performed by numerous testisspecific and/or germ cell-specific genes [4, 5]. Thus, identification and further characterization of testis- and germ cell-specific genes contribute greatly to our knowledge of spermatogenesis.

Rab GTPases, the largest family of small GTPases, are known as master regulators of intracellular membrane

\footnotetext{
* Correspondence: klee@chonnam.ac.kr

'Hormone Research Center, School of Biological Sciences and Technology,

Chonnam National University, Gwangju, Republic of Korea

Full list of author information is available at the end of the article
}

traffic $[6,7]$. In humans, this family is made up of approximately 70 members, subdivided into 44 subfamilies $[8,9]$. Rab proteins are present in all compartments of endomembrane system such as Golgi and endoplasmic reticulum, the nucleus, the plasma membrane, mitochondria and centrioles. In addition to their role in the extraordinary complex membrane trafficking circuit, the characterization of the Rab GTPases has revealed their diverse functions [10-12]. For example, Rab proteins have been identified to cross talk with different kinases and play a role in cellular signaling. Rab4, Rab5, Rab25 and Rab11 [13-17] have been associated with phosphoinositide kinases, Rab8 have been associated with germinal center kinases (GCKs) [18], Rab13 and Rab32 have been associated with Protein kinase A (PKA) [19, 20], and Rab2 has been associated with protein kinase C (PKC) [21]. Rab proteins have also been reported to have other functions, including nuclear signaling (Rab5, Rab8, Rab24 and others) [22, 23], regulation of mitochondrial fission 
(Rab32) [20], regulation of cell-matrix and cell-cell adhesion (Rab4a, Rab8b, Rab13 and Rab21) and involvement in cell growth and division or apoptosis (Rab6a, Rab11, Rab12, Rab23, Rab25, Rab35, Ran and others) [10, 24-29].

Among the Rab family of proteins, only a few are reported to be expressed in the testis. Small GTPase Rab12 is highly expressed in rat Sertoli cells and aids in the transport of vesicles from cellular fringe to perinuclear centrosome region [26]. Rab proteins have also been identified to have an important role in sperm development. Rab3A, a monomeric GTP binding protein, is expressed in the acrosomal membrane of mouse sperm and regulates zona pellucida-induced acrosomal exocytosis [30]. TBC1D9, a Rab GTPase accelerating protein (GAP), is abundantly expressed in spermatocytes and is reported to interact with Rab5, Rab7 and Rab9 [31]. Recently RabL2 has been shown to be essential for sperm tail function and male fertility [32]. In addition, Rab8B is known to assist in junction dynamics of the testis [33].

In the course of cloning androgen-induced genes from murine testis, we identified a gene encoding a protein with GTPase activity, which is likely a variant of the mouse homolog of human RASEF [34]. The expression of this gene was testis-specific; thus, it was named $T s g$ (testis-specific GTPase). TSG has a well conserved Rab domain which provides GTPase activity and classifies it among the members of the Rab/Ras family. Very limited numbers of Rab proteins have been associated with the testis. Thus, finding and characterization of a testisspecific Rab can aid our understanding of testicular development and spermatogenesis.

\section{Methods}

\section{Plasmids}

The mammalian expression vectors for full-length TSG, pCDNA3-HA-TSG and pCDNA3-FLAG-TSG were cloned by PCR amplification. For pCDNA-FLAG-coiled-coil, an internal XbaI site was used and the N-terminal 176 amino acids were cloned, which included the coiled-coil region from amino acid position 5 to 154 . For the coiled-coil deletion clone, the $\mathrm{N}$-terminal 176 amino acids were deleted, and the remaining residues were cloned into pCDNAFLAG vector. For antibody production, the PstI-digested fragment from residue $213-523$ was cloned into the pRSET-C at the PstI site. For immunocytochemistry and immunoprecipitation, either full-length or $\Delta \mathrm{N}$-terminal ( $\Delta 1-212)$ TSG was cloned into EGFP-C1 (Clontech).

\section{Screening of $\lambda$-testis cDNA library}

A mouse testis cDNA library in Lambda ZAP was purchased from Stratagene Inc. (La Jolla, CA, USA). Screening of $2.5 \times 10^{5}$ clones was done according to the manual. Briefly, the phage particles were immobilized on nylon membranes and then denatured in $0.5 \mathrm{M} \mathrm{NaOH}$ and $1.5 \mathrm{M} \mathrm{NaCl}$. They were then neutralized in $0.5 \mathrm{M}$ Tris ( $\mathrm{pH} 8.0$ ) and $1.5 \mathrm{M} \mathrm{NaCl}$. Following UV crosslinking, the filters were prehybridized and then hybridized at $42{ }^{\circ} \mathrm{C}$ in the presence of $5 \mathrm{X}$ standard saline citrate (SSC), $10 \%$ dextran sulfate, $1 \mathrm{mM}$ EDTA, 50 \% formamide, $10 \mathrm{mg} / \mathrm{ml}$ denatured salmon sperm DNA along with a random-primed $\left[{ }^{32} \mathrm{P}\right]$-dCTP-labeled mouse TSG cDNA probe. Filters were then washed and exposed for $36 \mathrm{~h}$ on Kodak X-ray film at $-70^{\circ} \mathrm{C}$. Secondary screening was performed to isolate single, pure phage plaques. Phase particles were used to recover the cDNA inserts as plasmids in the $\mathrm{pBS} \alpha \mathrm{SK}$ vector by in vivo excision [35].

\section{Cell culture}

Cos-7 and 293T cells were maintained in Dulbecco's minimum essential medium supplemented with $10 \%$ FBS and antibiotics. All cells were cultured at $37{ }^{\circ} \mathrm{C}$ under an atmosphere of $5 \% \mathrm{CO}_{2}$.

\section{Antibody production and purification}

pRSET-C TSG was transformed into BL-21 competent cells. Protein expression was induced using IPTG (Isopropyl $\beta$-D1-thiogalactopyranoside) and then purified using Ni-affinity chromatography. Eluted protein was submitted to Abfrontier (Gwangju, Republic of Korea) for antibody production in rabbits. Serum received from the company was affinitypurified using antigen immobilized on nitrocellulose membranes as previously described [36].

\section{In vitro translation}

TNT-coupled transcription-translation system (Promega) was used to perform in vitro translation reactions using $\left[{ }^{35} \mathrm{~S}\right]$-methionine according to the manufacturer's instructions. Samples were analyzed by SDS PAGE and developed by autoradiography [37].

\section{Northern blot analysis}

Total RNA was prepared from dissected tissues of C57BL/6 mice using Tri reagent (Molecular Research Center, Inc.). Total RNA (20 $\mu \mathrm{g})$ run in a $1.2 \%$ denaturing agarose gel was transferred to Zeta probe nylon membrane (Bio-Rad) and immobilized by UV crosslinking. Hybridization of membrane was done with random-primed $\alpha-\left[{ }^{32} \mathrm{P}\right]$-labeled TSG cDNA probes as described previously [38].

\section{Semi-quantitative reverse transcription polymerase chain reaction}

For RT-PCR, $2 \mu \mathrm{g}$ of total RNA was reverse transcribed and PCR amplified using Tsg specific primers. As internal control, $\beta$-actin-specific primers were used. The oligonucleotide sequences were as follows: forward 5'AGGGGCTTTTCCTGACAACT-3' and reverse 5'-ATT TCCAGATCCCGTTCAGA-3' for Tsg; forward 5'-GAG 
ACCTTCAACACCCCAGCC-3' and reverse 5'-CCGTC AGGCAGCTCATAGCTC-3' for $\beta$-actin.

\section{Western blot analysis}

TSG-transfected 293T cells were harvested using RIPA cell lysis buffer containing protease inhibitors. Total protein was separated by SDS-PAGE and transferred to nitrocellulose membrane (Whatman Protran) as described previously [39]. Western blot analyses were performed with purified anti-TSG antibody. The signals detection was done with an ECL kit (Amersham Pharmacia). For mouse tissue samples, total lysates from dissected tissues were prepared in RIPA cell lysis buffer as indicated.

\section{Immunohistochemistry}

Adult mouse testis was fixed in Bouin's solution and embedded in paraffin. For immunohistochemistry, $5 \mu \mathrm{m}$ sections were processed using the Histostain-Plus kit (Zymed Laboratories Inc.), according to the manufacturer's instructions. Briefly, deparaffinized and rehydrated slides from mouse testes sections were heated to boiling temperature in citrate buffer at $\mathrm{pH} 6.0$ and then maintained at sub-boiling temperature for 10 mins for antigen retrieval. These slides were processed with anti-TSG antibody, followed by the secondary antibody conjugated with Alexa 488 (Molecular Probes, Eugene, Oregon) for immuno-fluorescence as described [40]. TO-PRO-3 (Molecular Probes) was used to stain the nuclear DNA. Slides were examined under a laser scanning fluorescent microscope (Leica TCS SPE, Heerbrugg, Switzerland). For nuclear localization, GFP-tagged full-length TSG, $\Delta \mathrm{N}$ TSG and GFP were transfected into Cos-7 cells cultured on gelatin coated coverslips, which were then fixed with $4 \%$ paraformaldehyde and washed twice using PBS. The fixed cells were treated with $1 \%$ SDS in PBS (Phosphate buffer saline) for 5 mins and then washed three times with PBS. Washed cells were incubated for $30 \mathrm{~min}$ with TOPRO-3 at a 1:500 dilution in PBS and then washed twice with PBS. Coverslips were mounted on slides and analyzed with a laser scanning fluorescent microscope.

\section{Co-immunoprecipitation}

To investigate the interaction between coiled coil motifs, 293T cells were transfected with $2 \mu \mathrm{g}$ of each plasmid, pCDNA control, pCDNA FLAG-TSG, pCDNA HATSG, pCDNA-FLAG coiled-coil and pCDNA-FLAG deleted coil for $48 \mathrm{~h}$. Cells were lysed with RIPA buffer (50 mM TRIS pH 8, $150 \mathrm{mM} \mathrm{NaCl}$, and $1 \% \mathrm{NP}-40$ ) containing protease inhibitors. Whole-cell lysate $(500 \mu \mathrm{g})$ was incubated with $2 \mu \mathrm{g}$ of anti-HA (sc-7392X, Lot \# K0912) or anti-FLAG antibody (F7425, Sigma) overnight at $4{ }^{\circ} \mathrm{C}$ and incubated for an additional $2 \mathrm{~h}$ after adding $20 \mu \mathrm{l}$ of Protein A/G PLUS-agarose beads (Santa Cruz Biotechnology). Agarose beads were washed with IP wash buffer (40 mM HEPES (pH 7.7), $0.01 \%$ NP-40, $0.2 \mathrm{mM}$ EDTA, $5 \mathrm{mM} \mathrm{MgCl} 2,150 \mathrm{mM} \mathrm{NaCl}$ and $20 \%$ glycerol) containing protease inhibitors at $4{ }^{\circ} \mathrm{C}$ as previously described [41]. Bound proteins were analyzed using $10 \%$ SDS-PAGE and subsequent immunoblotting using anti-HA or anti-FLAG antibodies. For immunoprecipitation of actin-bound TSG, GFP or GFP-TSG, transfected Cos-7 cells were lysed and immunoprecipitated using antiGFP antibody and further immunoblotted using anti-actin (sc-1616) or anti-GFP antibody (sc-8334).

\section{GTPase assay}

Cos-7 cells transfected with pEGFP or pEGFP-TSG were lysed and immunoprecipitated using anti-GFP antibody. Beads were washed with IP lysis buffer and then with TMD buffer (50 mM Tris, pH 7.4, $10 \mathrm{mM} \mathrm{Mgcl2,} 1 \mathrm{mM}$ DTT). Collected beads were suspended in $100 \mathrm{mM}$ glycine and mixed. Supernatant was collected and neutralized with 0.1 volume of Tris base and mixed with 0.1 volume of 10X PBS. The eluted protein was incubated with $4 \mu \mathrm{Ci} \gamma-\mathrm{P}^{32}$ in an equal volume of TMD buffer. After $24 \mathrm{~h}$, the reaction was stopped by adding $2 \mu \mathrm{l}$ of $4 \%$ SDS. Samples were purified by phenol:chloroform extraction and eluted in a volume of $40 \mu \mathrm{l}$. The samples were subsequently mixed with an equal volume of watersaturated ether and allowed to stand for $5 \mathrm{~min}$, followed by collection of the lower phase and lyophilization by speed vac. The dried sample was dissolved in $2 \mu \mathrm{l}$ of sterile distilled water and then spotted on TLC plates. Signals were detected by autoradiography.

\section{Results}

\section{Chromosomal organization of TSG}

$T s g$ is present on chromosome 4 in the mouse genome. It consists of 16 exons, and the translation start site lies in the $2^{\text {nd }}$ exon, while the stop codon is found in the $16^{\text {th }}$ exon (Fig. 1a). The mRNA has an open reading frame of 1593 base pairs, encoding a protein of 530 amino acids. The TSG protein shares $100 \%$ identity with a part of RASEF in mouse (NP_001017427.1), the predicted homolog of human RASEF. RASEF is also known as Rab45, and belongs to the Rab family of GTPases. The main difference between the predicted mouse RASEF and TSG lies in the size of mRNA. Mouse Rasef is predicted to generate an mRNA of 5183 base pairs, which encodes a protein of 627 amino acids, while the $T s g$ has an open reading frame (ORF) of 2159 bp spanning from nucleotides 257 to 1849 , which encodes a protein of 530 amino acids (Additional file 1). The marked difference lies within the N-terminal 97 amino acids of the predicted RASEF, which is missing in TSG. This difference is due to the use of an alternative transcription initiation site and the alternative exon 1 of $T s g$ mRNA, which results in translation initiation at an 


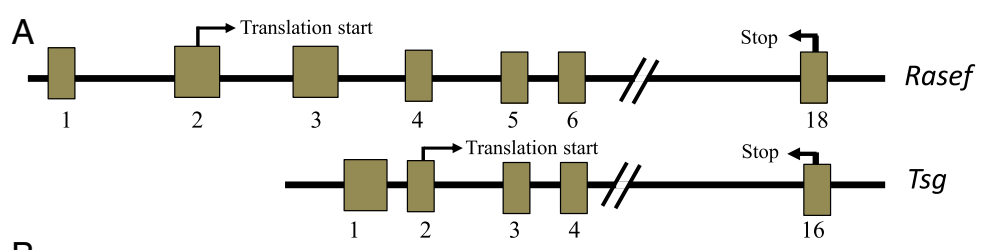

B

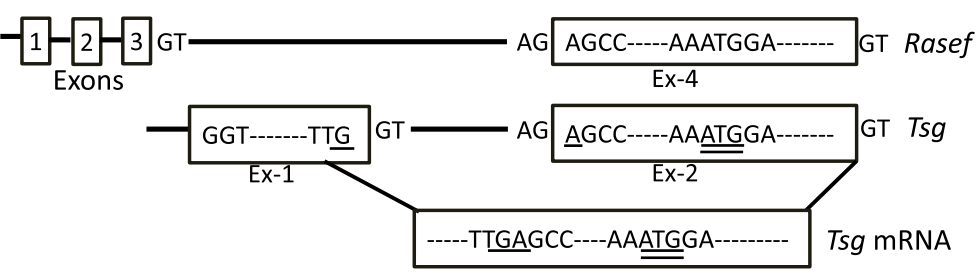

Fig. 1 Exonic organization of Rasef and Tsg. The size of boxes corresponds to the size of exons, while the space between the boxes corresponds the introns for the genomic organization of predicted mouse Rasef (top) and Tsg (bottom) (a) Representation of the first two exons of Tsg in comparison with the first four exons of Rasef. The in-frame upstream stop codon and the start codon for Tsg are underlined with single and double lines, respectively (b)

internal Met codon of RASEF, thereby restricting the size of protein (Fig. 1b). TSG shares more than $80 \%$ identity with the human RASEF, while the expression of RASEF has not yet been confirmed in mouse.

\section{Expressional analysis of TSG}

The expression of Tsg was examined in different tissues by northern blot analysis (Fig. 2a). Expression was confined to the testis with no expression in somatic tissues or ovary. Tissue level RT-PCR analysis also confirmed the male specificity with expression confined to the testis (Fig. 2b). Northern blotting revealed two larger transcripts that hybridized with the cDNA probe of $T s g$, which could be either Tsg mRNA precursors, variants of Tsg mRNA or homologous transcripts including mouse
Rasef. The expression of TSG in the testis is developmentally regulated, appearing approximately $24 \mathrm{dpp}$ (Fig. 2c). The major change during this period in testicular development is the appearance of haploid round spermatids which appears approximately 20 dpp [42]. RT-PCR analysis confirms the appearance of the Tsg transcript at 19 21 dpp, which continues to increase with development (Fig. 2d).

At the protein level, TSG shows a similar expression pattern as the RNA. The expression is specific to the testis, but with a higher molecular weight than expected (Fig. 3a). To verify the size of TSG, we performed in vitro translation using a cDNA clone. The result confirmed two different sizes of the protein: the expected size of approximately $58 \mathrm{kDa}$ and a second of approximately
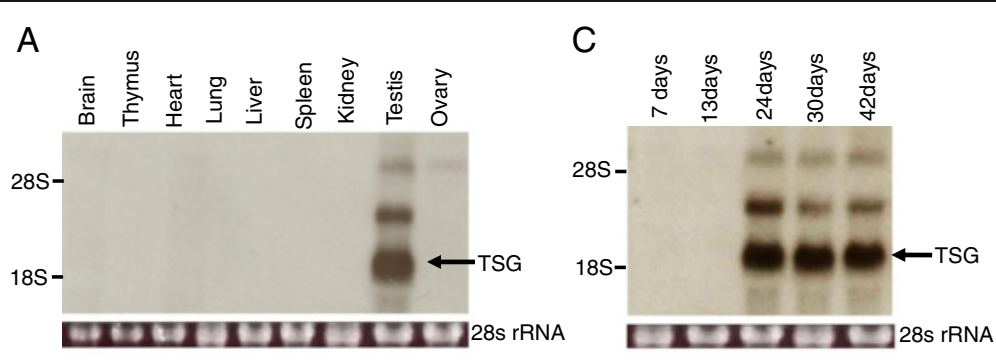

B

D
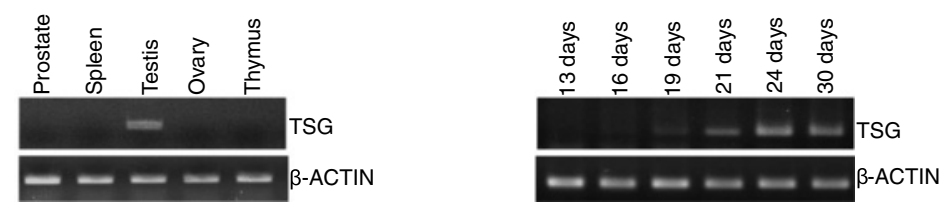

Fig. 2 Expression analysis of TSG in mouse tissues and developing testis. Total RNAs used in northern blot analysis were isolated from various tissues of adult mice and $28 \mathrm{~S}$ rRNA was used as a loading control (a) Expression of Tsg is specific to the testis as analyzed in different tissues of 6-week-old mice by RT-PCR. $\beta$-actin was used as an endogenous control (b) Total RNAs from the indicated age of developing testis were used for the analysis (c) Expressional analysis of Tsg in the indicated aged testis by RT-PCR (d) 


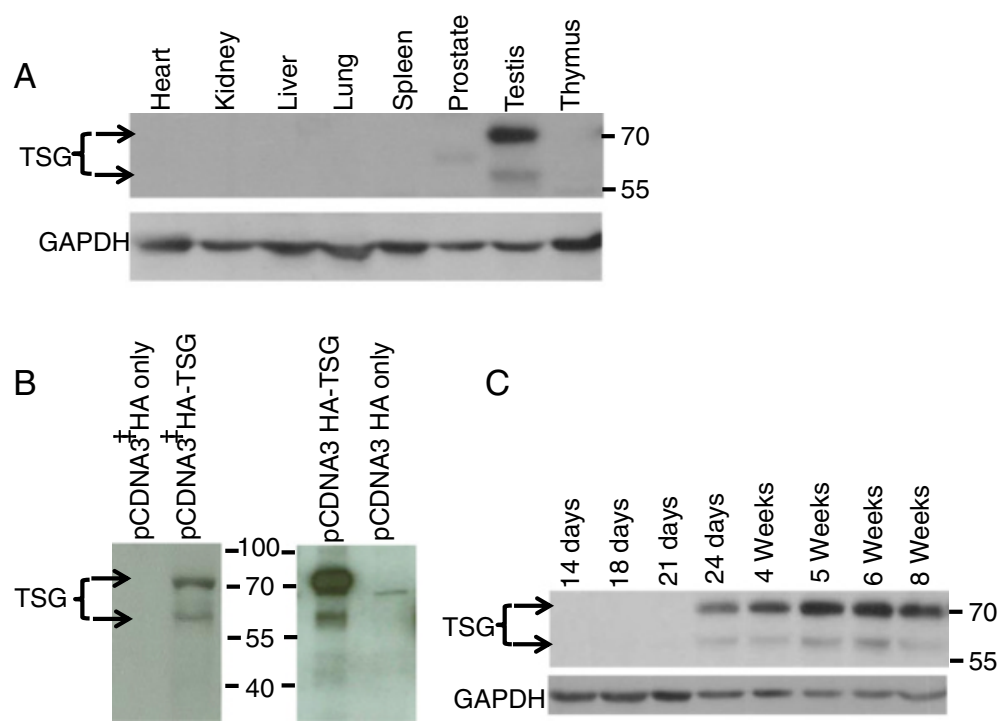

Fig. 3 Expression of TSG protein in mouse tissues and developing testis. TSG exists as a higher molecular weight form in the testis (a) In vitro translation using radioactively labelled methionine clearly shows two forms of TSG produced from the CDNA clone after autoradiography. Similar forms of TSG were detected using anti-TSG antibody in immunoblot analyses using the lysates of 293T cells transfected with HA-tagged TSG. (†) stands for samples of in vitro translation using radioactive methionine. Empty pCDNA HA vector was used as a negative control (b) TSG expression during testis development (c)

$72 \mathrm{kDa}$ (Fig. 3b, left panel). Similar sized proteins were visualized in the lysate of TSG-overexpressing $293 \mathrm{~T}$ cells, which was immunoblotted using purified TSG antibody (Fig. 3b, right panel). The expression of TSG in the testis was detected at 24 days (Fig. 3c). Furthermore, immunohistochemistry was performed to analyze the expression of TSG in the testis. The immunofluorescent localization confirmed expression, mainly confined to germ cells, particularly in elongating spermatids (Fig. 4). TSG transcripts seem to be under translational regulation because the messages are expressed earlier than protein detection, at $19 \sim 21 \mathrm{dpp}$ when round spermatids are developing. Due to the limited transcriptional activity in elongating spermatids, messenger RNAs for many proteins expressed in elongating spermatids are actually produced in round spermatids and undergo translational repression until development has reached the elongating spermatid stage [43].

\section{Domain analysis}

Architecture domain analysis of TSG using the SMART database (http://smart.embl-heidelberg.de/) revealed a coiled-coil motif present in the N-terminus of TSG (Fig. 5). Further motif scan analysis (http://myhits.isb-sib.ch/cgibin/motif_scan) ascertained the presence of a bipartite nuclear targeting sequence, suggesting that TSG is a nuclear-targeted protein. The coiled-coil motif extends from amino acid residues 5 to 154, with the nuclear
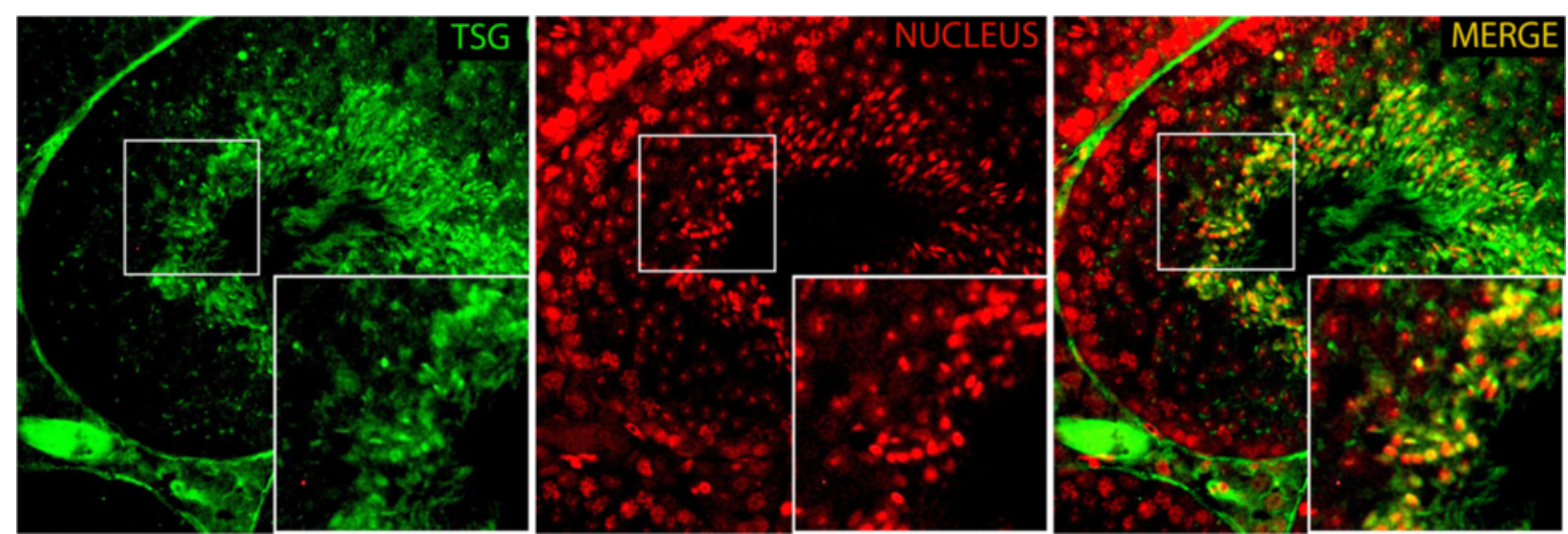

Fig. 4 TSG is highly expressed in elongating spermatids. Immunofluorescence of the adult testis sections of mice showing stage VII tubule with Alexa 488 anti-TSG antibody (GREEN; left), TO-PRO-3 (RED, middle) and merge (right). Inset represents a higher magnification 


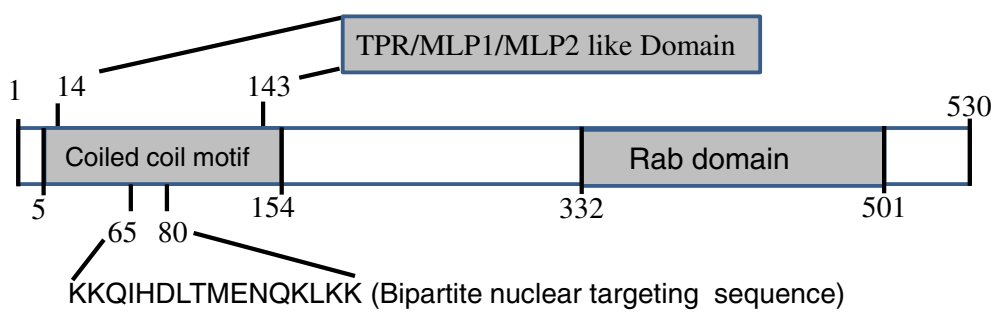

Fig. 5 Structural organization of TSG protein. The N-terminal region harbors the coiled-coil motif and the C-terminus contains the Rab domain. Bipartite nuclear targeting sequence is located in the middle of coiled-coil motif. The coiled-coil region also harbors the TPR/MLP1/MLP2-like domain

targeting sequence embedded extending from residues 65 to 80 . The coiled-coil motif region also harbors a TPR/ MLP1/MLP2-like domain, which is a feature of myosinlike proteins. The C-terminus of TSG contains the Rab/ Ras GTPase domain, which is evolutionarily conserved.

\section{Self-interaction of TSG through the coiled-coil motif} TSG is detected at a higher molecular weight than expected in the testis (Fig. 3b). Therefore, we sought to determine whether TSG is capable of undergoing selfinteraction and, if so, whether the coiled-coil motif of TSG is involved in that interaction. To investigate this, we prepared full-length TSG constructs tagged with FLAG or HA and TSG deletion mutants lacking the coiled-coil motif or containing only the coiled-coil motif. HA-tagged full-length TSG was expressed with FLAGtagged full-length or deletion mutants of TSG in 293T cells, and the cell lysates were subjected to immunoprecipitation using anti-HA (Fig. 6a) or anti-FLAG antibody (Fig. 6b). FLAG-tagged full-length TSG as well as the isolated coiled-coil domain interacts with HA-tagged full-length TSG, while the TSG deletion mutant lacking the coiled-coil motif loses the ability to interact with full-length TSG. These results show that TSG is able to form multimers through the coiled-coil motif and suggest that this property may be the reason for the higher than predicted molecular weight form of TSG.

\section{TSG is a nuclear protein}

TSG contains a nuclear localization signal (NLS). In addition, immunohistochemical analysis of TSG expression in the testis showed that TSG is localized to the elongating spermatids (Fig. 4). Therefore, we validated the functionality of the NLS using a TSG deletion construct, lacking the most $\mathrm{N}$-terminal region containing the NLS. The N-terminus-deleted GFP-tagged TSG clone was restricted from the nucleus and remained distributed in the cytoplasm, while the full-length GFPtagged protein was localized to the nucleus (Fig. 7).

\section{TSG has GTPase activity}

Proteins containing the Rab domain have been shown to have GTPase activity. TSG contains a Rab domain at the C-terminus; thus, we expected it to display GTPase activity. To verify the GTPase activity, pEGFP only or pEGFP-TSG fusion protein constructs were expressed in

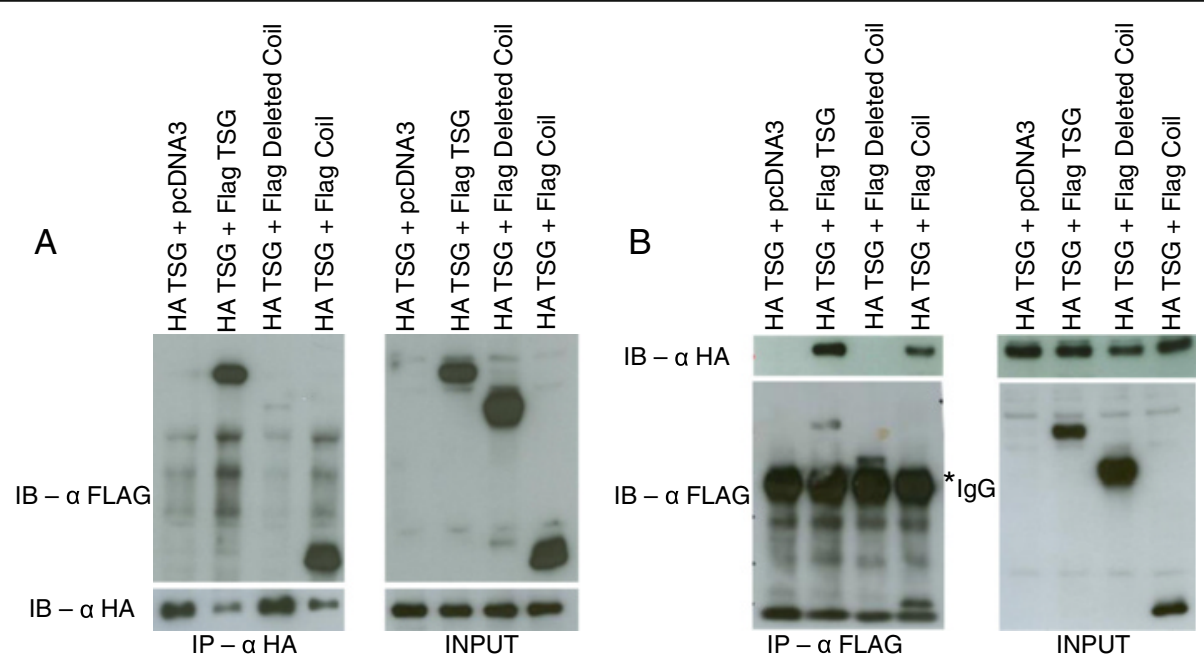

Fig. 6 TSG is able to self-interact through the coiled-coil motif. Immunoprecipitation using anti-HA antibody (a) or anti-FLAG antibody (b) The immunoprecipitates were analyzed by western blotting using anti-FLAG and anti-HA antibodies. All HA- and FLAG-tagged constructs were cloned into the pCDNA3 vector, and $5 \%$ of the total protein was taken as input. The asterisk (*) represents the non-specific lgG 

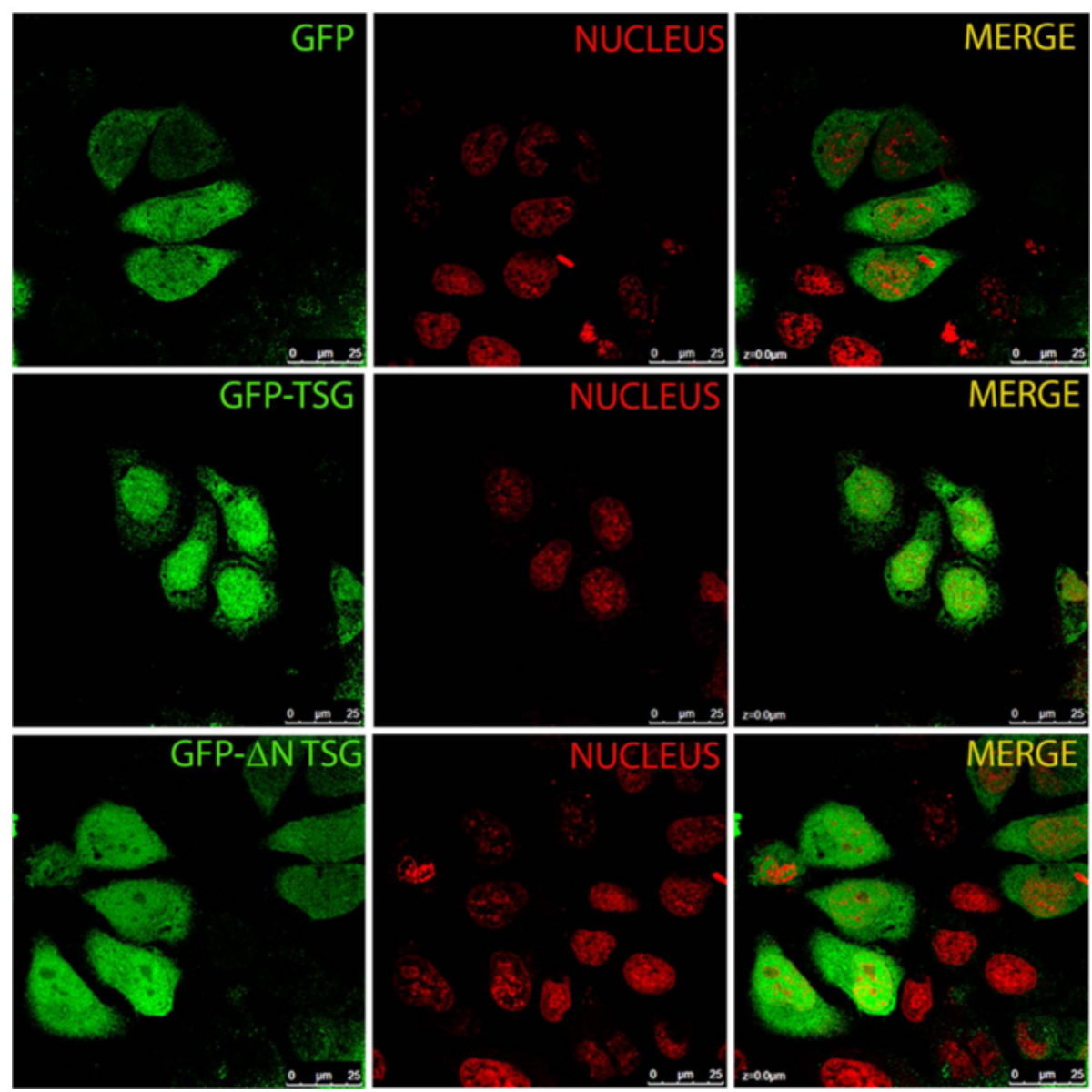

Fig. 7 TSG is likely a nuclear protein. GFP-tagged TSG expressed exogenously in HeLa cells was concentrated predominantly in the nucleus (Green) while N-terminus-deleted TSG was localized to the cytoplasm similar to GFP (Green) only. Nuclear DNA was stained using TO-PRO-3 (Red)

Cos-7 cells, and the cell lysates were immunoprecipitated using anti-GFP antibody. The eluted protein was incubated with $\gamma$ - $\left[\mathrm{P}^{32}\right]$-labeled GTP for $24 \mathrm{~h}$. The GFPtagged TSG released the $\gamma$ - $\left[\mathrm{P}^{32}\right]$ from GTP, which was detected by thin-layer chromatography (Fig. 8a).

\section{Myosin-like property}

Myosin is a motor protein that utilizes the energy from ATP hydrolysis to move along the actin filament. TSG has a TPR/MLP1/MLP2-like domain, which is a feature of myosin-like proteins. To confirm the myosin-like

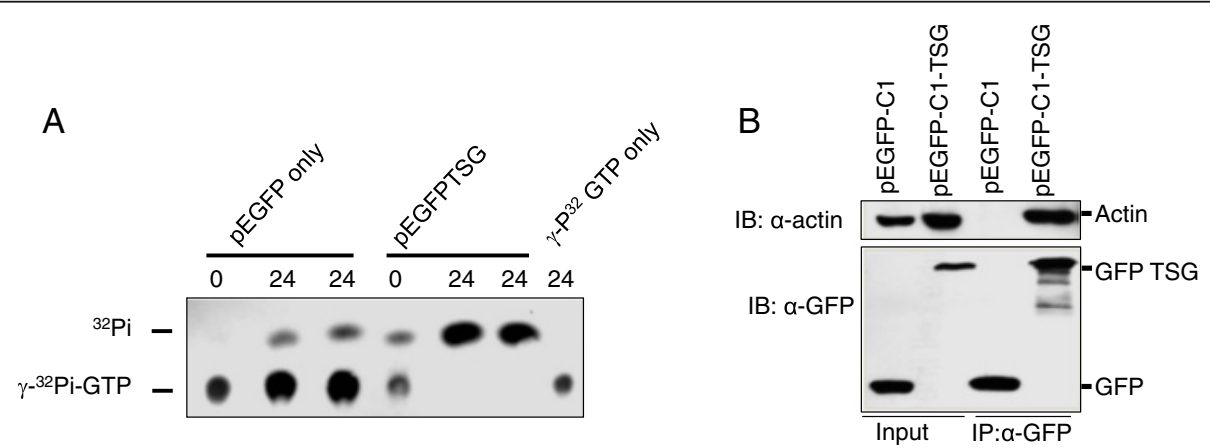

Fig. 8 Functional characteristics of TSG. TSG has GTPase activity. The extract from Cos-7 cells transfected with pEGFP or pEGFP-TSG was incubated with $\gamma^{-}{ }^{32}$ P]-GTP for $24 \mathrm{~h}$ and then subjected to TLC (a) TSG binds to actin inside the cell. Cos-7 cells were transfected with GFP only or with GFP-TSG, and lysates were immunoprecipitated with anti-GFP antibody. A total of $10 \%$ of the sample was loaded as input (b) 
property, we performed a co-immunoprecipitation experiment using Cos-7 cells transfected with GFP-tagged TSG or GFP vector only. The cell lysate with GFP-TSG expression was immunoprecipitated with anti-GFP antibody, and GFP-TSG was co-immunoprecipitated with actin protein, while no such interaction was seen in the lysate expressing only GFP (Fig. 8b). These results indicate the possibility for TSG to behave like myosin protein.

\section{Discussion}

Several Rab proteins and Rab effectors have been reported to form oligomers and the self-interacting property of these proteins are important for their function. For example, RILP forms a homodimer to interact with Rab7, and disruption of dimerization abolishes its interaction with Rab7 [44]. A family of Rab11interacting proteins (FIPs) has also been reported to have the ability to self-interact [45-47]. Human RASEF has been characterized as a self-associating GTPase localized in perinuclear area of cells [34]. The mouse homologue of RASEF has not yet been verified, but the predicted protein reported in the NCBI database is completely identical to TSG except for an additional 90 amino acids located at its N-terminus and thus is predicted to selfinteract as shown for TSG. As per our analysis, TSG is highly expressed in the testis and is a nuclear localizing GTPase because deletion of the bipartite nuclear localization signal restricts its localization to the cytoplasm. Conversely the human RASEF is ubiquitously expressed and localized to the membrane. Both of these proteins share a Rab domain at the $\mathrm{C}$-terminus and thus have GTPase activity.

Proteins with coiled-coil motifs typically have a role in membrane traffic and have functionally distinct domains at their N- or C-terminus [48]. Rabaptin5, a large coiledcoil protein, has a distinct $\mathrm{N}$ and $\mathrm{C}$ terminal domains that binds to Rab4 and Rab5 respectively [49]. Rab45, also called human RASEF, has an EF-hand domain at the N-terminus, and a Rab homology domain in the Cterminus [34]. In the same manner, the predicted mouse RASEF has an EF-hand domain as well as a Rab domain, but TSG lacks the EF-hand domain, which makes it different from RASEF. Mouse RASEF, if verified, may show membrane localization similar to the human RASEF. However, we cannot rule out the possibility that mouse RASEF is a nuclear-targeted protein because the bipartite nuclear localization sequence found in TSG is also present in the predicted RASEF protein, while human RASEF completely lacks this sequence.

Human RASEF is a 740 amino acid protein with an expected molecular weight of approximately $81 \mathrm{kDa}$, but the wild type clone expressed in HeLa cells was actually observed to be approximately $100 \mathrm{kDa}$ [34]. Similarly,
TSG is a 530 amino acid protein and is expected to have a size of $58 \mathrm{kDa}$, but it appears as a mixture of both $72 \mathrm{kDa}$ and $58 \mathrm{kDa}$; the reason might be its selfinteracting property. When we checked the protein expression level in mouse testis, the majority of the protein appears as the high molecular weight form, while a very small, almost undetectable, portion of the expected size is observed. This suggests true functionality of this protein in the testis because most coiled-coil proteins need to self-interact and form oligomers to be functional. Such self-interacting proteins lose their function when the interaction is abolished [44]. The appearance of this protein in the elongating spermatids after three weeks of murine testis development indicates its importance in later stages of germ cell development. In the course of germ cell development in the testis, round spermatids appear around $20 \mathrm{dpp}$ and the condensing/elongated spermatids start to appear around $24 \mathrm{dpp}$. The final spermatozoa are released at $35 \mathrm{dpp}$ [42].

Myosins consist of ATP-dependent proteins that are involved in a wide range of cell motility processes as well as muscle contraction. Heavy chains of Myosin have three chiseled regions: the motor, neck, and tail domains [50]. The motor domain binds to actin in an ATPdependent manner [51, 52]. The neck domain accords the binding of light chains and assists as a lever arm to permit movement of motor domain [51]. The tail domain is the most variable region of myosins with various lengths and functions depending on the motifs present in its sequence, such as coiled-coil dimerization regions, MyTH4, FERM, or SH3 domains for protein-protein interactions [51]. TSG does not have the head region of myosin but it still interacts with actin, which suggests TSG may be part of complex which functions as a GTPase protein. GTPases are known to complex with myosin $[53,54]$. The rat myosin protein myr5 has been described as a GTPase activation protein in vivo [55]. TbRab23 is a nuclear-associated Rab protein that renders stability to nuclear structure [56]. There are recent reports identifying multiple Rab proteins that interact with myosin Va. Lindsay et al. screened all human Rab proteins for the ability to bind myosin $\mathrm{Va}$ and revealed an interaction with Rab3B, 3C, 6A, 6A', 6B, 11B, 14, 25 and $39 \mathrm{~B}$ [57]. This report adds to the previously reported interactions of Rab3A, 8A, 10, 11A and 27A with myosin Va [58-61].

\section{Conclusion}

In the present study, we have elaborated the expression and localization of TSG, a protein with GTPase activity and self-interacting properties capable of forming oligomers. The germ cell-specific expression of TSG makes it an attractive candidate to address its biological role during testicular germ cell development. 


\section{Additional file}

Additional file 1: Nucleotide and amino acid sequences of TSG. Complete mRNA sequence and the deduced amino acid sequence identified for TSG having the start and the stop codon underlined and bolded. (DOCX $13 \mathrm{~kb}$ )

\section{Abbreviations}

Dpp: Days postpartum; GAP: GTPase accelerating protein; GCKs: Germinal center kinases; IPTG: Isopropyl $\beta$-D-1-thiogalactopyranoside; NLS: Nuclear localization signal; ORF: Open reading frame; PBS: Phosphate buffer saline; PKA: Protein Kinase A; PKC: Protein kinase C; Rab: Ras-related proteins in brain; RASEF: RAS and EF hand domain containing; SSC: Standard saline citrate; TSG: Testis-specific GTPase

\section{Acknowledgement}

The research was supported by National Research Foundation of Korea (NRF) as well as research grant from Chonnam National University to Prof Keesook Lee.

\section{Funding}

This research was supported by Basic Science Research Program through the National Research Foundation of Korea (NRF) funded by the Ministry of Education, Science and Technology (NRF- 2014R1A4A1003642) and by a grant from Chonnam National University.

\section{Availability of data and materia}

The identified mRNA sequence and the corresponding protein sequence have been provided as supplementary material with the article.

\section{Authors' contributions}

SK, HJL and KL conceived the idea and designed the experiments; SK and HJL carried out the experiments; SK, HSP and KL analyzed the data; SK, HSP and KL drafted the manuscript. All authors read and approved the final manuscript.

\section{Competing interest}

The authors declare that there is no conflict of interest that could be perceived as prejudicing the impartiality of the research presented.

\section{Consent for publication}

Not applicable.

\section{Ethics approval and consent to participate}

All animal procedures were approved by the Institutional Animal Care and Use Committee (IACUC) of Chonnam National University (Permit Number: 2012-44).

\section{Data deposition}

The complete mRNA sequence and deduced corresponding protein sequence has been submitted to Genbank (NCBI) with submission ID:\#1918733.

\section{Author details}

'Hormone Research Center, School of Biological Sciences and Technology, Chonnam National University, Gwangju, Republic of Korea. ${ }^{2}$ Department of Nursing, Dongkang College, Gwangju, Republic of Korea.

Received: 13 May 2016 Accepted: 30 September 2016

\section{Published online: 10 October 2016}

\section{References}

1. Schultz N, Hamra FK, Garbers DL. A multitude of genes expressed solely in meiotic or postmeiotic spermatogenic cells offers a myriad of contraceptive targets. Proc Natl Acad Sci U S A. 2003;100(21):12201-6.

2. O'Shaughnessy PJ, Willerton L, Baker PJ. Changes in Leydig cell gene expression during development in the mouse. Biol Reprod. 2002;66(4):966-75.

3. Rolland AD, Jegou B, Pineau C. Testicular development and spermatogenesis: harvesting the postgenomics bounty. Adv Exp Med Biol. 2008:636:16-41.

4. Sha J, Zhou Z, Li J, Yin L, Yang H, Hu G, Luo M, Chan HC, Zhou K. Identification of testis development and spermatogenesis-related genes in human and mouse testes using cDNA arrays. Mol Hum Reprod. 2002;8(6):511-7.
5. Eddy EM. Male germ cell gene expression. Recent Prog Horm Res. 2002;57: 103-28.

6. Stenmark H. Rab GTPases as coordinators of vesicle traffic. Nat Rev Mol Cell Biol. 2009;10(8):513-25.

7. Wandinger-Ness A, Zerial M. Rab proteins and the compartmentalization of the endosomal system. Cold Spring Harb Perspect Biol. 2014:6(11):a022616.

8. Zhen Y, Stenmark H. Cellular functions of Rab GTPases at a glance. J Cell Sci. 2015:128(17):3171-6.

9. Diekmann Y, Seixas E, Gouw M, Tavares-Cadete F, Seabra MC, Pereira-Leal JB. Thousands of rab GTPases for the cell biologist. PLoS Comput Biol. 2011; 7(10):e1002217.

10. Bucci C, Chiariello M. Signal transduction gRABs attention. Cell Signal. 2006; 18(1):1-8.

11. Zerial M, McBride H. Rab proteins as membrane organizers. Nat Rev Mol Cell Biol. 2001;2(2):107-17.

12. Schwartz SL, Cao C, Pylypenko O, Rak A, Wandinger-Ness A. Rab GTPases at a glance. J Cell Sci. 2007;120(Pt 22):3905-10.

13. Shibata H, Omata W, Kojima I. Insulin stimulates guanine nucleotide exchange on Rab4 via a wortmannin-sensitive signaling pathway in rat adipocytes. J Biol Chem. 1997;272(23):14542-6.

14. Christoforidis S, Miaczynska M, Ashman K, Wilm M, Zhao L, Yip SC, Waterfield MD, Backer JM, Zerial M. Phosphatidylinositol-3-OH kinases are Rab5 effectors. Nat Cell Biol. 1999;1(4):249-52.

15. Knight JB, Cao KT, Gibson GV, Olson AL. Expression of a prenylationdeficient Rab4 interferes with propagation of insulin signaling through insulin receptor substrate-1. Endocrinology. 2000;141(1):208-18.

16. Cheng KW, Lahad JP, Kuo WL, Lapuk A, Yamada K, Auersperg N, Liu J, SmithMcCune K, Lu KH, Fishman D, et al. The RAB25 small GTPase determines aggressiveness of ovarian and breast cancers. Nat Med. 2004;10(11):1251-6.

17. de Graaf P, Zwart WT, van Dijken RA, Deneka M, Schulz TK, Geijsen N, Coffer PJ, Gadella BM, Verkleij AJ, van der Sluijs P, et al. Phosphatidylinositol 4kinasebeta is critical for functional association of rab11 with the Golgi complex. Mol Biol Cell. 2004;15(4):2038-47.

18. Ren M, Zeng J, De Lemos-Chiarandini C, Rosenfeld M, Adesnik M, Sabatini DD. In its active form, the GTP-binding protein rab8 interacts with a stressactivated protein kinase. Proc Natl Acad Sci U S A. 1996:93(10):5151-5.

19. Kohler K, Louvard D, Zahraoui A. Rab13 regulates PKA signaling during tight junction assembly. J Cell Biol. 2004;165(2):175-80.

20. Alto NM, Soderling J, Scott JD. Rab32 is an A-kinase anchoring protein and participates in mitochondrial dynamics. J Cell Biol. 2002;158(4):659-68.

21. Tisdale EJ. Rab2 interacts directly with atypical protein kinase C (aPKC) iota/ lambda and inhibits aPKCiota/lambda-dependent glyceraldehyde-3-phosphate dehydrogenase phosphorylation. J Biol Chem. 2003;278(52):52524-30.

22. Miaczynska M, Christoforidis S, Giner A, Shevchenko A, Uttenweiler-Joseph S, Habermann B, Wilm M, Parton RG, Zerial M. APPL proteins link Rab5 to nuclear signal transduction via an endosomal compartment. Cell. 2004;116(3):445-56.

23. Wu M, Yin G, Zhao X, Ji C, Gu S, Tang R, Dong H, Xie Y, Mao Y. Human RAB24, interestingly and predominantly distributed in the nuclei of COS-7 cells, is colocalized with cyclophilin A and GABARAP. Int J Mol Med. 2006:17(5):749-54

24. Del Nery E, Miserey-Lenkei S, Falguieres T, Nizak C, Johannes L, Perez F, Goud B. Rab6A and Rab6A' GTPases play non-overlapping roles in membrane trafficking. Traffic. 2006;7(4):394-407.

25. Fan $Y$, Xin XY, Chen BL, Ma X. Knockdown of RAB25 expression by RNAi inhibits growth of human epithelial ovarian cancer cells in vitro and in vivo. Pathology. 2006;38(6):561-7.

26. lida H, Noda M, Kaneko T, Doiguchi M, Mori T. Identification of rab12 as a vesicle-associated small GTPase highly expressed in Sertoli cells of rat testis. Mol Reprod Dev. 2005;71(2):178-85.

27. Kouranti I, Sachse M, Arouche N, Goud B, Echard A. Rab35 regulates an endocytic recycling pathway essential for the terminal steps of cytokinesis. Curr Biol. 2006;16(17):1719-25.

28. Wang Y, Ng EL, Tang BL. Rab23: what exactly does it traffic? Traffic. 2006; 7(6):746-50.

29. Yu X, Prekeris R, Gould GW. Role of endosomal Rab GTPases in cytokinesis. Eur J Cell Biol. 2007;86(1):25-35.

30. Ward CR, Faundes D, Foster JA. The monomeric GTP binding protein, rab3a, is associated with the acrosome in mouse sperm. Mol Reprod Dev. 1999; 53(4):413-21.

31. Nakamura Y, Asano A, Hosaka Y, Takeuchi T, Iwanaga T, Yamano Y. Expression and intracellular localization of TBC1D9, a Rab GTPaseaccelerating protein, in mice testes. Exp Anim. 2015;64(4):415-24. 
32. Lo JC, Jamsai D, O'Connor AE, Borg C, Clark BJ, Whisstock JC, Field MC, Adams V, Ishikawa T, Aitken RJ, et al. RAB-like 2 has an essential role in male fertility, sperm intra-flagellar transport, and tail assembly. PLoS Genet. 2012; 8(10):e1002969.

33. Lau AS, Mruk DD. Rab8B GTPase and junction dynamics in the testis. Endocrinology. 2003;144(4):1549-63

34. Shintani M, Tada M, Kobayashi T, Kajiho H, Kontani K, Katada T. Characterization of Rab45/RASEF containing EF-hand domain and a coiledcoil motif as a self-associating GTPase. Biochem Biophys Res Commun. 2007;357(3):661-7.

35. Jeong BC, Hong CY, Chattopadhyay S, Park JH, Gong EY, Kim HJ, Chun SY, Lee K. Androgen receptor corepressor-19 kDa (ARR19), a leucine-rich protein that represses the transcriptional activity of androgen receptor through recruitment of histone deacetylase. Mol Endocrinol. 2004;18(1):13-25.

36. Sambrook J, Maniatis T, Fritsch EF. Molecular cloning : a laboratory manual. 2nd ed. Cold Spring Harbor: Cold Spring Harbor Laboratory; 1989.

37. Qamar I, Gong EY, Kim Y, Song CH, Lee HJ, Chun SY, Lee K. Antisteroidogenic factor ARR19 inhibits testicular steroidogenesis through the suppression of Nur77 transactivation. J Biol Chem. 2010;285(29):22360-9.

38. Gong EY, Park E, Lee HJ, Lee K. Expression of Atp8b3 in murine testis and its characterization as a testis specific P-type ATPase. Reproduction. 2009; 137(2):345-51.

39. Chattopadhyay S, Gong EY, Hwang M, Park E, Lee HJ, Hong CY, Choi HS, Cheong JH, Kwon HB, Lee K. The CCAAT enhancer-binding protein-alpha negatively regulates the transactivation of androgen receptor in prostate cancer cells. Mol Endocrinol. 2006;20(5):984-95.

40. Gong EY, Park E, Chattopadhyay S, Lee SY, Lee K. Gene expression profile of rat prostate during pubertal growth and maturation. Reprod Sci. 2011;18(5):426-34.

41. Park E, Kim Y, Lee HJ, Lee K. Differential regulation of steroidogenic enzyme genes by TRalpha signaling in testicular Leydig cells. Mol Endocrinol. 2014; 28(6):822-33.

42. Desjardins C, Ewing LL. Cell and molecular biology of the testis. New York ; Oxford: Oxford University Press; 1993.

43. Steger K. Transcriptional and translational regulation of gene expression in haploid spermatids. Anat Embryol. 1999;199(6):471-87.

44. Wu M, Wang T, Loh E, Hong W, Song H. Structural basis for recruitment of RILP by small GTPase Rab7. EMBO J. 2005;24(8):1491-501.

45. Wallace DM, Lindsay AJ, Hendrick AG, McCaffrey MW. The novel Rab11-FIP/ Rip/RCP family of proteins displays extensive homo- and hetero-interacting abilities. Biochem Biophys Res Commun. 2002;292(4):909-15.

46. Eathiraj S, Mishra A, Prekeris R, Lambright DG. Structural basis for Rab11mediated recruitment of FIP3 to recycling endosomes. J Mol Biol. 2006; 364(2):121-35

47. Shiba T, Koga H, Shin HW, Kawasaki M, Kato R, Nakayama K, Wakatsuki S. Structural basis for Rab11-dependent membrane recruitment of a family of Rab11-interacting protein 3 (FIP3)/Arfophilin-1. Proc Natl Acad Sci U S A. 2006;103(42):15416-21.

48. Gillingham AK, Munro S. Long coiled-coil proteins and membrane traffic. Biochim Biophys Acta. 2003;1641(2-3):71-85.

49. Vitale G, Rybin V, Christoforidis S, Thornqvist P, McCaffrey M, Stenmark H, Zerial M. Distinct Rab-binding domains mediate the interaction of Rabaptin5 with GTP-bound Rab4 and Rab5. EMBO J. 1998;17(7):1941-51.

50. Krendel M, Mooseker MS. Myosins: tails (and heads) of functional diversity. Physiology (Bethesda). 2005;20:239-51.

51. Mooseker MS, Foth BJ. The structural and functional diversity of the myosin family of actin-based molecular motors. In: Myosins. Netherlands: Springer; 2008: pp. 1-34.

52. Vale RD. The Molecular Motor Toolbox for Intracellular Transport. Cell. 2003; 112(4):467-80

53. Jin $Y$, Sultana A, Gandhi P, Franklin E, Hamamoto S, Khan Amir R, Munson M, Schekman R, Weisman Lois S. Myosin V Transports Secretory Vesicles via a Rab GTPase Cascade and Interaction with the Exocyst Complex. Dev Cell. 2011;21(6):1156-70.

54. Itoh T, Watabe A, Toh EA, Matsui Y. Complex formation with Ypt11p, a rabtype small GTPase, is essential to facilitate the function of Myo2p, a class $V$ myosin, in mitochondrial distribution in Saccharomyces cerevisiae. Mol Cell Biol. 2002;22(22):7744-57.

55. Muller RT, Honnert U, Reinhard J, Bahler M. The rat myosin myr 5 is a GTPase-activating protein for Rho in vivo: essential role of arginine 1695 Mol Biol Cell. 1997:8(10):2039-53.
56. Dhir V, Field MC. TbRAB23; a nuclear-associated Rab protein from Trypanosoma brucei. Mol Biochem Parasitol. 2004;136(2):297-301.

57. Lindsay AJ, Jollivet F, Horgan CP, Khan AR, Raposo G, McCaffrey MW, Goud B. Identification and characterization of multiple novel Rab-myosin Va interactions. Mol Biol Cell. 2013;24(21):3420-34.

58. Roland JT, Lapierre LA, Goldenring JR. Alternative splicing in class V myosins determines association with Rab10. J Biol Chem. 2009;284(2):1213-23.

59. Wollert T, Patel A, Lee YL, Provance Jr DW, Vought VE, Cosgrove MS, Mercer JA, Langford GM. Myosin5a tail associates directly with Rab3A-containing compartments in neurons. J Biol Chem. 2011;286(16):14352-61.

60. Fukuda M, Kuroda TS, Mikoshiba K. Slac2-a/melanophilin, the missing link between Rab27 and myosin Va: implications of a tripartite protein complex for melanosome transport. J Biol Chem. 2002;277(14):12432-6.

61. Wu XS, Rao K, Zhang H, Wang F, Sellers JR, Matesic LE, Copeland NG, Jenkins NA, Hammer 3rd JA. Identification of an organelle receptor for myosin-Va. Nat Cell Biol. 2002;4(4):271-8.

\section{Submit your next manuscript to BioMed Central and we will help you at every step:}

- We accept pre-submission inquiries

- Our selector tool helps you to find the most relevant journal

- We provide round the clock customer support

- Convenient online submission

- Thorough peer review

- Inclusion in PubMed and all major indexing services

- Maximum visibility for your research

Submit your manuscript at www.biomedcentral.com/submit
) Biomed Central 